\title{
Panel of Oxidative Stress and Inflammatory Biomarkers in ALS: A Pilot Study
}

\author{
Hélène Blasco, Guillaume Garcon, Franck Patin, Charlotte Veyrat-Durebex, \\ Judith Boyer, David Devos, Patrick Vourc'h, Christian R. Andres, Philippe Corcia
}

\begin{abstract}
Background: Pathophysiological mechanisms that contribute to neurodegeneration in Amyotrophic Lateral Sclerosis (ALS) include oxidative stress and inflammation. We conducted a preliminary study to explore these mechanisms, to discuss their link in ALS, and to determine the feasibility of incorporating this combined analysis into current biomarkers research. Methods: We enrolled 10 ALS patients and 10 controls. We measured the activities of glutathione peroxidase, glutathione reductase, superoxyde dismutase (SOD), and the levels of serum total antioxidant status (TAS), malondialdehyde (MDA), 8-hydroxy-2'-deoxyguanosine (8-OHdG), and glutathione status (e.g. glutathione disulfide, GSSG/reduced glutathione, GSH). We analysed the concentrations of homocysteine, several cytokines, vitamins and metals by standard methods used in routine practice. Results: There was a significant decrease in TAS levels $(\mathrm{p}=0.027)$ and increase in $8-\mathrm{OHdG}(\mathrm{p}=0.014)$ and MDA $(\mathrm{p}=0.011)$ levels in ALS patients. We also observed a significantly higher GSSG/GSH ratio $(p=0.022)$, and IL-6 $(p=0.0079)$ and IL-8 $(p=0.009)$ concentrations in ALS patients. Correlations were found between biological and clinical markers (homosysteine vs. clinical status at diagnosis, $\mathrm{p}=0.02$ ) and between some biological markers such as IL-6 vs. GSSG/GSH $(\mathrm{p}=0.045)$ or SOD activity $(\mathrm{p}=0.017)$. Conclusion: We confirmed the systemic alteration of both the redox and the inflammation status in ALS patients, and we observed a link with some clinical parameters. These promising results encourage us to pursue this study with collection of combined oxidative stress and inflammatory markers.
\end{abstract}

RÉSUMÉ: Détermination d'un panel de biomarqueurs du stress oxydant et de l'inflammation dans la SLA: une étude pilote. Contexte: Parmi les mécanismes impliqués dans la physiopathologie de la Sclérose Latérale Amyotrophique (SLA), on note un stress oxydant et des mécanismes inflammatoires. Nous avons ainsi mené une étude préliminaire afin de 1) d'explorer ces mécanismes, 2) de discuter leur lien dans la SLA, 3) de déterminer la faisabilité d'une telle analyse combinée pour une utilisation courante en recherche de biomarqueurs. Méthodes: Nous avons inclus prospectivement 10 patients SLA et 10 contrôles. Nous avons mesuré l'activité des enzymes suivantes : glutathion peroxydase, glutathion réductase, superoxyde dismutase (SOD), et les concentrations sériques des paramètres suivants : statut antioxydant total (SAT), malondialdéhyde (MDA), 8-hydroxy-2'-déoxyguanosine (8-OHdG), et le statut en glutathion (e.g. glutathione oxydé, GSSG/glutathione réduit, GSH). Nous avons analysé les concentrations d'homocystéine, de plusieurs cytokines, de vitamines et de différents métaux par des méthodes validées en routine. Résultats: Nous avons montré une diminution significative du SAT (p=0.027) et une augmentation de la 8-OHdG $(\mathrm{p}=0.014)$ ainsi que du MDA $(\mathrm{p}=0.011)$ chez les patients SLA. Nous avons observé une augmentation du rapport GSSG/GSH $(p=0.022)$, ainsi que des concentrations d'IL-6 $(p=0.0079)$ et d'IL-8 ( $p=0.009)$ chez les patients SLA. Des corrélations ont été observées entre certains marqueurs biologiques et cliniques (homosysteine vs sévérité de la pathologie au diagnostic, $\mathrm{p}=0.02$ ) mais également entre les marqueurs biologiques entre eux tels que l'IL-6 vs GSSG/GSH (p=0.045) ou vs l'activité de la SOD ( $\mathrm{p}=0.017)$. Conclusion: Nous avons confirmé l'altération du statut redox et la composante inflammatoire importante dans la SLA, en dehors du SNC. Nous avons également observé un lien entre certains paramètres cliniques et biologiques, ce qui nous incite à poursuivre cette étude en analysant la combinaison de ces marqueurs de stress oxydant et d'inflammation.

Keywords: oxidative stress, ALS, biomarkers, neuroinflammation, homocysteine, vitamin

doi:10.1017/cjn.2016.284

Can J Neurol Sci. 2017; 44: 90-95

\section{INTRODUCTION}

Amyotrophic lateral sclerosis (ALS), the most common adultonset motor neuron disease, is characterized by degeneration of upper and lower motor neurons in the brain and spinal cord. Median survival is 2-5 years after symptom onset, but survival times can range from a few months to several decades. ${ }^{1}$ Although

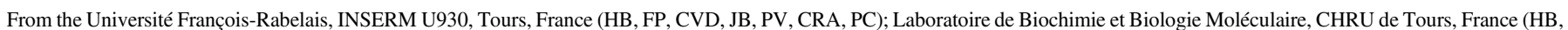
PV, CRA); EA4483, Université de Lille 2, Lille, France (GG, DD); Centre SLA, Service de Neurologie, CHRU Bretonneau, Tours, France (PC).

Received January 6, 2016. Revised April 15, 2016. Date of Acceptance June 23, 2016.

Correspondence to: Hélène BLASCO, Laboratoire de Biochimie et Biologie moléculaire, Hôpital Bretonneau, CHRU de Tours ; 2, Bd Tonnellé, 37044 - Tours cedex 1, France.

Tel.: + 332474737 95. Fax: + 332474786 13. Email: helene.blasco@univ-tours.fr. 
many of the cellular processes leading to demise of motor neurons are still not completely understood, several genetic mutations and environmental risk factors have been related to the pathogenesis. ${ }^{2}$ Irrespective of the cause, downstream pathophysiological events that contribute to neurodegeneration in ALS include oxidative stress and glutamate-mediated excitotoxicity, as well as activation of pro-inflammatory mediators. However, the interaction between these events in this complex disease is still an enigma. Oxidative stress that includes protein injury, ${ }^{3}$ lipid peroxidaion, ${ }^{4}$ DNA damage $^{5}$ and RNA oxidation ${ }^{6}$ has been reported in patients with either familial (FALS) or sporadic (SALS). ALS.Oxidative stress biomarkers in SALS patients have been repeatedly found in urine, Cerebro Spinal Fluid (CSF), blood, tissues, individually or together, such as elevated malondialdehyde (MDA) modified protein, nuclear DNA 8-hydroxy-2'-deoxyguanosine (8-OHdG) ${ }^{7}$ and total antioxidant status (TAS). Low levels of erythrocyte glutathione, low activity of erythrocyte glutathione peroxydase (GPX) and superoxyde dismutase 1 (SOD1) ${ }^{8}$ have also been described, but some discrepancies related to these findings have been reported. Interestingly, mitochondrial damage and oxidative stress play a major role in ALS even in non-SOD1-dependent cases. ${ }^{9}$ Numerous environmental factors may contribute to oxidative stress and preclude a discussion of the direct alteration of oxidative stress status. For example some studies found increased concentrations of homocysteine in ALS correlated with progression, ${ }^{10}$ alterations of vitamin and metals levels, ${ }^{11}$ all mechanisms able to modify oxidative status of patients. Inflammation, another major pathophysiological process involved in ALS, has been reported by fundamental studies of cultured cells, animal models and clinical studies in humans. ${ }^{12}$ Although oxidative stress and inflammation are non- ALS-specific, their exploration may improve the knowledge of ALS pathogenesis. Thus we conducted a preliminary study to identify some relevant blood markers of oxidative stress and inflammation, and to discuss their link to ALS. Such explorations may help identify circulating biomarkers useful in routine practice. We aim to determine the feasibility of incorporating these techniques into biomarkers research. The findings of this pilot study could also suggest some possible pathophysiological pathways.

\section{METHOD \\ Patients}

We enrolled 10 patients with definite or probable sporadic ALS according to the revised El Escorial criteria. ${ }^{13}$ All patients were evaluated in the ALS center of Tours, France, in 2014. The site of onset was defined as bulbar or limb. Age at onset was defined as the time of occurrence of first motor weakness noted by the patient. We determined the Revised ALS Functional Rating Scale score (ALSFRS-r score) at diagnosis as well as its change during the first six months after diagnosis and the progression rate (48-ALSFRS) at diagnosis/disease evolution. We also collected data on degree of weight loss at diagnosis (calculated as the weight at diagnosis subtracted from the usual adult weight reported by the patient), considered an excellent nutrition and prognosis marker in ALS. Patients were screened for C9ORF72, SOD1, FUS, and TDP43 gene mutations. All patients were treated with riluzole from the date of blood collection, corresponding to the diagnosis date. We also recruited 10 gender and age-matched controls without any neurological disorders. We collected data about smoking for all subjects. No subject was taking vitamin $\mathrm{E}$ supplements.

Blood samples obtained during routine examination of patients at diagnosis were prospectively collected and the remaining volume was used for research. Blood samples were collected with the same procedures in patients and controls. The Ethics Committee of Tours Hospital approved the research on samples collected for routine care. Each participant signed a consent form after reviewing the details of the study.

\section{Markers of oxidative stress}

In order to monitor the biological effect of therapeutic aganes we chose different markers of oxidative stress according to 1) the relevance of these biomarkers to ALS, 2) their capacity to accurately identify oxidative stress, 3) the reliability of the measurement method and 4) the opportunity to suggest new therapeutic targets.

TAS was studied in serum as previously described. ${ }^{14}$ Glutathione disulfide (GSSG) and reduced glutathione (GSH) levels in whole blood, MDA levels in plasma, and 8-OHdG levels in serum were determined according to published methods. ${ }^{15,16,17}$ Antioxidant enzyme activities of SOD, GPX and GR in whole blood were carried out using commercially available kits (Sigma-Aldrich, Saint-Quentin-Fallavier, France). The methemoglobincyanide method was used to determine $\mathrm{Hb}$ contents in whole blood.

\section{Other parameters}

We measured the concentrations of 5 vitamins: serum and erythrocyte B9, B12 (Immulite 2000 ${ }^{\circledR}$, Siemens Healthcare, France), A, E, C (High Performance Liquid Chromatography, Chromsystems Instruments and Chemicals $\mathrm{GmbH}$, Germany), homocysteine (Liquid chromatography coupled with mass spectrometry) and the following metals: $\mathrm{Cu}, \mathrm{Zn}, \mathrm{Mn}$, Se (Atomic Emission Spectrometry

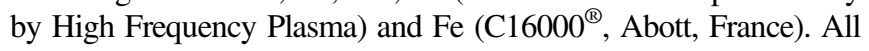
these methods are standard and validated for routine practice with rigorous quality programs and are accredited or in the course of accreditation by the National Quality Program (France).

Cytokine concentrations (Tumor Necrosis Factor-alpha, TNF $\alpha$; Interleukin-8, IL-8; Interleukin-6, IL-6; Interleukin-10, IL-10) in serum were determined using a MILLIPLEX ${ }^{\circledR}$ MAP Human Cytokine/Chemokine Magnetic Bead Panel-Immunology Multiplex Assay (Millipore SAS, Molsheim, France).

\section{Statistical analysis}

Biochemical variables were compared between ALS patients and controls using a non-parametric Wilcoxon test. Correlation between levels of oxidative stress markers and quantitative clinical and biological variables was analyzed by Spearman's rho correlation.

The significance threshold was set at $\mathrm{p}<0.05$. We performed a pilot study with numerous tests on a small population; therefore, in order to clearly reveal the trends, we did not apply a restrictive correction for multiple test. This correction will be used in a second step when we will confirm the findings on a larger cohort. Statistical analyses were performed with JMP ${ }^{\circledR} 7.0$ software (SAS Institute $^{\circledR}$, Cary, U.S.A.). 
Table 1: Characteristics of ALS patients and controls

\begin{tabular}{l|c|c|c}
\hline & ALS patients & Controls & p-value \\
\hline Age (mean, SD) & $65.7+/-15.0$ & $65.4+/-13.8$ & 0.9 \\
\hline Gender & & & \\
\hline male, $\mathrm{n}(\%)$ & $4(44.4)$ & $6(40)$ & $6(60)$ \\
\hline female, $\mathrm{n}(\%)$ & $5(55.6)$ & & \\
\hline Site at onset & & & \\
\hline spinal, $\mathrm{n}(\%)$ & $6(66.7)$ & & \\
\hline bulbar, $\mathrm{n}(\%)$ & $3(33.3)$ & & \\
\hline ALSFRS at diagnosis (mean $+/-S D)$ & $41.3+/-3.7$ & & \\
\hline ALSFRS decline over 6 months, \% (mean+/-SD) & $7.2+/-8.7$ & & \\
\hline Progression rate & $1.1+/-0.2$ & & \\
\hline Weight of loss at the diagnosis (mean percentage +/-SD) & $2.8+/-4.7$ & & \\
\hline
\end{tabular}

\section{RESULTS}

\section{Patient characteristics}

We used the data from 9 ALS patients and 10 controls. We excluded one of the 10 recruited patients because the evolution of the disease did not confirm the ALS diagnosis. The characteristics of subjects are shown in Table 1. The median delay between the first symptoms and the diagnosis was 17.8 months. Mean ALSFRS-r score at diagnosis ranged from 35 to 46 and weight loss at diagnosis from 0 to $7.4 \%$. The median ALSFRS-r decline was $3.8 \%$ and ranged from 0 to $20.9 \%$. The percentage of smokers was similar in ALS and controls (about 20\%). No patient had mutation in C9ORF72, SOD1, FUS and TDP43 genes.

\section{Elevated oxidative stress in ALS patients}

The comparison of oxidative stress markers between ALS patients and controls is shown in Table 1. There was a significant decrease in TAS levels in ALS patients compared to controls $(\mathrm{p}=0.027)$. Despite no significant change in antioxidant enzyme activities, the glutathione status was altered in ALS patients, with elevated concentrations of GSSG $(p=0.034)$ and lower

Table 2: Comparison of oxidative stress markers between ALS patients and controls

\begin{tabular}{l|l|l|c}
\hline & \multicolumn{1}{|c|}{ ALS patients } & \multicolumn{1}{c}{ Controls } & p-value \\
\hline TAS $(\mathrm{mmol}$ Trolox/L) & $1.72+/-0.12$ & $1.84+/-0.16$ & 0.027 \\
\hline SOD $(\mathrm{UI} / \mathrm{g} \mathrm{Hb})$ & $866.32+/-173.17$ & $827.55+/-184.57$ & 0.93 \\
\hline GR $(\mathrm{UI} / \mathrm{g} \mathrm{Hb})$ & $6.63+/-2.87$ & $7.08+/-2.86$ & 0.62 \\
\hline GPx $(\mathrm{UI} / \mathrm{g} \mathrm{Hb})$ & $82.28+/-29.81$ & $72.33+/-23.88$ & 0.41 \\
\hline GSH $(\mu \mathrm{M})$ & $31.78+/-4.98$ & $42.09+/-9.44$ & 0.022 \\
\hline GSH $(\mu \mathrm{mol} / \mathrm{g} \mathrm{Hb})$ & $0.23+/-0.05$ & $0.31+/-0.07$ & 0.034 \\
\hline GSSG $(\mu \mathrm{M})$ & $11.58+/-3.13$ & $8.94+/-1.64$ & 0.034 \\
\hline GSSG $(\mu \mathrm{mol} / \mathrm{g} \mathrm{Hb})$ & $0.08+/-0.02$ & $0.07+/-0.014$ & 0.034 \\
\hline GSSG/GSH & $0.38+/-0.13$ & $0.23+/-0.09$ & 0.022 \\
\hline $8-\mathrm{OHdG}(\mathrm{ng} / \mathrm{mL})$ & $1.61+/-0.58$ & $0.98+/-0.28$ & 0.014 \\
\hline MDA $(\mu \mathrm{M})$ & $0.44+/-0.08$ & $0.35+/-0.06$ & 0.011 \\
\hline
\end{tabular}

concentrations of GSH $(\mathrm{p}=0.034)$, leading to a significantly higher GSSG/GSH ratio $(\mathrm{p}=0.022)$. There were also deleterious effects of oxidative stress in ALS patients, including elevated concentrations of $8-\mathrm{OHdG}$ and MDA $(\mathrm{p}=0.014$ and 0.011 , respectively, Table 2).

\section{Elevated inflammation in ALS patients}

The comparison of inflammatory markers between ALS patients and controls is shown in Table 3. We did not detect any sign of systemic inflammation (normal values CRP and leucocytes-not shown). We observed significantly higher concentrations of IL-6 $(p=0.0079)$ and IL-8 $(p=0.009)$ and a trend to higher concentrations of TNF $\alpha$ in ALS patients $(p=0.06)$.

\section{Other related factors}

The measurement of all other parameters-metals, vitamins and metabolic markers-are summed up in Table 4. We did not observe any difference in homocysteine, vitamin and metals concentrations between ALS patients and controls.

\section{Relation between biological and clinical parameters}

We found an inverse relation between homocysteine concentrations and ALSFRS-r at diagnosis $\left(\mathrm{R}^{2}=0.55, \mathrm{p}=0.02\right)$ (Figure 1A) and a positive correlation between $\mathrm{Cu}$ levels and ALFRS-r decline $\left(\mathrm{R}^{2}=0.84, \mathrm{p}=0.0037\right.$ ) (Figure 1B).

Table 3: Comparison of inflammatory markers between ALS patients and controls

\begin{tabular}{l|l|l|l}
\hline & ALS patients & Controls & p-value \\
\hline $\mathrm{TNF} \alpha(\mathrm{pg} / \mathrm{mL})$ & $33.82+/-31.26$ & $16.80+/-11.54$ & 0.06 \\
\hline $\mathrm{IL}-8(\mathrm{pg} / \mathrm{mL})$ & $100.62+/-227.48$ & $12.72+/-7.88$ & 0.009 \\
\hline $\mathrm{IL}-10(\mathrm{pg} / \mathrm{mL})$ & $3.16+/-3.29$ & $2.29+/-2.09$ & 0.68 \\
\hline $\mathrm{IL}-6(\mathrm{pg} / \mathrm{mL})$ & $36.58+/-50.63$ & $9.07+/-3.99$ & 0.0006 \\
\hline
\end{tabular}


Table 4: Exploration of other factors : metal, vitamin, and homocysteine measurement

\begin{tabular}{l|l|l|l}
\hline & \multicolumn{1}{|c|}{ ALS patients } & \multicolumn{1}{c}{ Controls } & p-value \\
\hline Metals & & & \\
\hline $\mathrm{Cu}(\mathrm{mg} / \mathrm{L})$ & $1.14+/-0.22$ & $0.98+/-0.09$ & 0.07 \\
\hline $\mathrm{Zn}(\mathrm{mg} / \mathrm{L})$ & $0.89+/-0.12$ & $0.90+/-0.12$ & 0.86 \\
\hline $\mathrm{Mn}(\mu \mathrm{g} / \mathrm{L})$ & $1.8+/-0.55$ & $1.62+/-0.36$ & 0.15 \\
\hline $\mathrm{Se}(\mu \mathrm{g} / \mathrm{L})$ & $108.75+/-17.14$ & $106.4+/-13.82$ & 0.89 \\
\hline $\mathrm{Fe}(\mu \mathrm{mol} / \mathrm{L})$ & $3.7+/-2.90$ & $1.82+/-0.83$ & 0.38 \\
\hline Vitamins & & & \\
\hline sera B9 $(\mathrm{nmol} / \mathrm{L})$ & $19+/-10.70$ & $21.6+/-8.49$ & 0.33 \\
\hline erythrocyte B9 $(\mathrm{nmol} / \mathrm{L})$ & $916.44+/-604.32$ & $979.8+/-442.82$ & 0.57 \\
\hline B12 $(\mathrm{pmol} / \mathrm{L})$ & $413+/-163.02$ & $369.3+/-210.54$ & 0.37 \\
\hline A $(\mu \mathrm{mol} / \mathrm{L})$ & $1.83+/-0.56$ & $1.85+/-0.53$ & 0.68 \\
\hline E $(\mu \mathrm{mol} / \mathrm{L})$ & $41.81+/-33.40$ & $21.22+/-3.92$ & 0.51 \\
\hline $\mathrm{C}(\mu \mathrm{mol} / \mathrm{L})$ & $59.29+/-19.22$ & $55.81+/-16.43$ & 0.81 \\
\hline Metabolic marker & & & \\
\hline Homocysteine $(\mu \mathrm{mol} / \mathrm{L})$ & $12.89+/-3.33$ & $12.2+/-2.35$ & 0.97 \\
\hline
\end{tabular}

\section{Relation between markers of oxidative stress and inflammation}

We found a positive correlation between IL-6 concentrations and the ratio GSSG/GSH $\left(\mathrm{R}^{2}=0.46, \mathrm{p}=0.045\right)$ and an inverse correlation between IL-6 concentrations and SOD activity $\left(\mathrm{R}^{2}=0.58, \mathrm{p}=0.017\right.$ ) (Figures $2 \mathrm{~A}$ and $\left.2 \mathrm{~B}\right)$. Importantly, we did not observe any significant relation between these parameters in controls. There is substantial evidence implicating oxidative stress as a central mechanism in ALS patients, the ultimate trigger that causes increased ROS levels is still largely unknown, leading to speculation as to whether oxidative stress is a primary cause of the disease or merely a consequence of some other toxic insult. Moreover, it is still unclear whether oxidative stress is involved outside of the CNS; reliable oxidative stress biomarkers, especially blood biomarkers, are the first essential step to ascertaining such extra-CNS involvement. A better understanding of oxidative stress may also help to suggest some therapeutic targets and to act upstream of cellular damage.

This pilot study suggests that oxidative stress and inflammatory parameters are relevant factors in the evaluation of ALS.
Although performed on a small sample, the strengths of this study are the exploration of multiple parameters outside of the CNS such as oxidative stress and inflammatory factors and the concomitant evaluation of other factors (e.g. enzyme cofactors, metabolic parameters) that is rarely performed.

We found a significant decrease of TAS levels in ALS patients, suggesting a serious imbalance between the production of ROS and the ability of the system to remove or repair the damage. Most studies, including ours, are unanimous about the types of biological consequences of oxidative stress. We noted elevated concentration of $8-\mathrm{OHdG}$ that characterizes the oxidative injury to DNA and higher concentrations of MDA considered as a product of lipid peroxydation. A compelling study published by Bogdanov et al., ${ }^{18}$ notably found that plasma levels of $8-\mathrm{OHdG}$ in ALS were significantly higher than in the group with no neurological disorders but not in the group with other neurological disorders. Moreover, Mitsumoto et $a .^{19}$ revealed increased urinary 8-OHdG. Oxidative stress reactions can also significantly alter membrane structure and intracellular lipids, resulting in altered fluidity, permeability, transport and metabolic processes. ${ }^{20}$ Fatty acid peroxides can give rise to a variety of aldehydes, such as 4-hydroxy-2-nonenal (HNE) ${ }^{20}$ and thiobarbituric acid-reactive substances (TBARS) like MDA, that are not only end products and remnants of lipid peroxidation processes but also "second cytotoxic messengers." Moreover GSH, a free-radical scavenger tripeptide that regulates the intracellular redox state, was reported lower in ALS, associated with an increase of its oxidized form that could be deleterious for the disease evolution. ${ }^{21,22,23}$ We confirmed these findings with a significantly increased GSSG/GSH ratio in ALS patients. Contrary to other reports we did not observe any alteration of GR, GPX and SOD1 activity in ALS patients. ${ }^{22}$ However, the role played by SOD1 in ALS is not clear in the literature. According to one report SOD1 is not particularly protected against its inactivation by ROS, a process that could contribute to its partial inactivation. ${ }^{24}$ The genetic status of SOD1 or the state of the disease at the time of exploration may explain the discrepancies between studies. We also have to take into account that numerous studies about oxidative stress are preliminary, with a small number of patients, different methodologies and often without exploring the enzyme cofactors.

Moreover, we reported no statistically significant change in the levels of the vitamins A, C, and E in the sera of ALS patients as compared to controls. These three vitamins are generally considered to be some of the more biologically active nonenzymatic antioxidant. ${ }^{25}$ Vitamin E might have a protective role
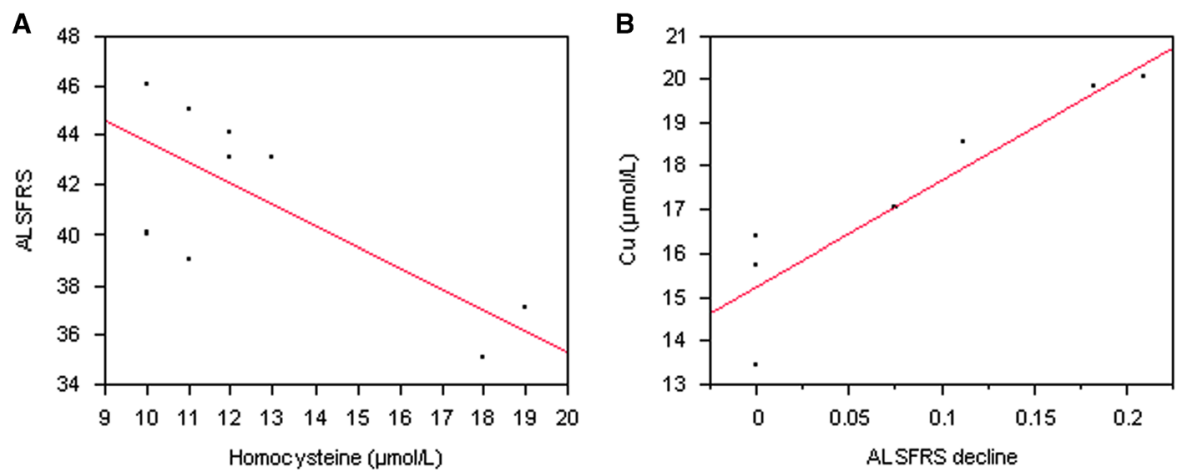

Figure 1: Correlation between biological and clinical parameters A: ALSFRS-r at diagnostic vs homocysteine levels $(p=0.02), B:$ ALSFRS-r decline vs Cu levels $(p=0.0037)$. 

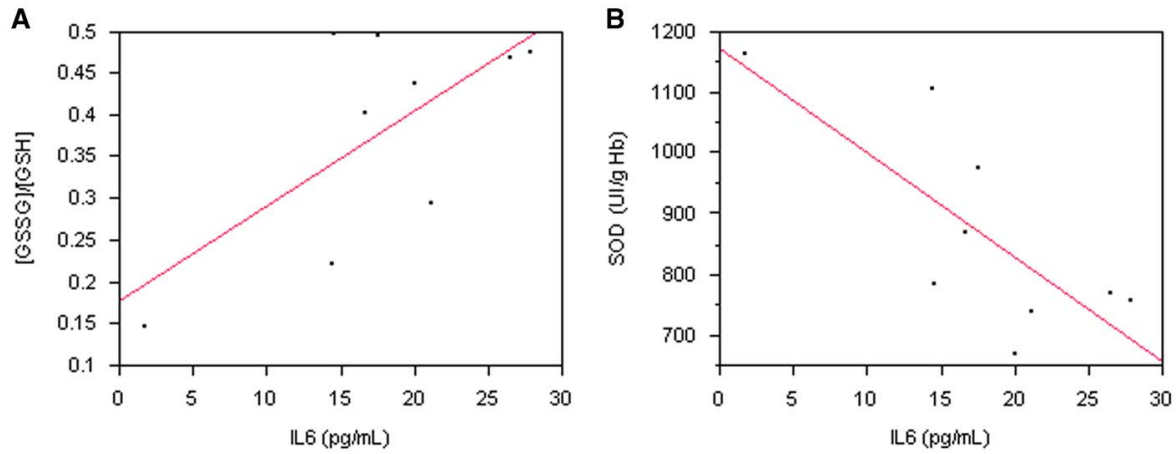

Figure 2: Correlation between oxidative stress and inflammatory markers : A GSSG/GSH vs IL-6 levels $(p=0.045), B:$ SOD activity vs IL-6 levels $(p=0.017)$.

in preventing the development of ALS while also slowing disease progression, but this effect is controversial. ${ }^{26}$

Interestingly, we did not find any significant increase in homocysteine and metals concentrations as observed in some other studies. ${ }^{27}$ According to other authors, however, exposure to metals ${ }^{28}$ is a suspect in the search for the cause of ALS, ${ }^{11}$ with many case reports linking different metals to ALS. In ALS there may be a direct link between iron, oxidative stress and regional neurodegeneration. ${ }^{24}$ The findings about oxidative stress were reinforced by the absence of the influence of enzyme cofactors or other sources of oxidative stress. This study is a proof of concept that the exploration of all these markers of oxidative stress could be feasible and independently from some other factors linked to this way.

Neuroinflammation in now established as an important factor in the pathogenesis of ALS We observed higher concentrations of IL-6, and IL-8 that have been previously described ${ }^{29}$ and that confirmed the pro- inflammatory and/or hypoxemia state of ALS patients at the first stage of the disease. The role of IL-6 in several neurological diseases and its link with iron metabolism led some authors to target these ways, such as the blockade of IL-6 signalisation. ${ }^{30}$ Recent research showed that this neuroinflammatory component is affected by the peripheral immune system; T lymphocytes in particular are able to cross into the brain and spinal cord parenchyma, where they interact with resident microglia, either inducing them to adopt an M1(cytotoxic) or M2 (protective) phenotype, depending on the stage of disease. Interestingly, TNF- $\alpha$ could trigger the induction of oxidative stress in a mechanism involving the NF- $\mathrm{\kappa B}$ signalling pathway which could be deregulated in ALS. ${ }^{31}$ These data link two important pathogenic mechanisms, oxidative stress and neuroinflammation, suggested to play a role in ALS. ${ }^{32}$ Hence, taken together, our data confirmed oxidative stress as well as inflammation status in the system outside of central nervous system as advocated by Mistumoto et al. ${ }^{19}$

Oxidative stress and inflammation are non-ALS-specific but the connection between these and disease progression such as weight loss and decline of ALSFRS-r score may be fruitful to investigate in $\mathrm{ALS}^{33}$ For example the association between homocysteine and diagnosis ALSFRS as well as between copper level and ALSFRS-r decline are relevant and consistent with previous findings. ${ }^{21,34,35,36}$ The limited number of enrolled ALS patients precluded an analysis of the relation between biological markers and long-term disease evolution.

\section{Conclusion and Future Perspective}

Although non-specific, we observed elevated of oxidative stress and inflammation and a link between some clinical parameters in ALS. Further investigations could help us better understand the link between these mechanisms and iron metabolism as well as the mitochondrial functions, with the aim of identifying the primary and secondary phenomena. All these parameters are probably associated with several factors that contribute to motor neurodegeneration but they have to be included in prognosis studies. These promising results encourage us to follow this study with collection of combined inflammatory and oxidative stress markers, confusion factors and clinical data to rigorously evaluate these relationships. This pilot study is promising but its small size limits the scope of our findings, which need to be further validated. After validation on an independent and larger cohort, the biomarkers identified in this study could also be useful in clinical trials to define some subgroups of patients based on inflammatory and redox status. The strategy of using combined biological markers has to be tested with other types of biomarkers (e.g. metabolic) to more accurately define some biological phenotypes. The most promising opportunity offered by this kind of study would be the identification of new therapeutic targets. Note that numerous therapeutic antibodies have been designed and may target some relevant inflammatory biomarkers identified in ALS and also in other neurological diseases such as Alzheimer's disease or Multiple Sclerosis.

\section{Disclosures}

Hélène Blasco, Guillaume Garcon, Franck Patin, Charlotte Veyrat-Durebex, Charlotte Veyrat-Durebex, Judith Boyer, David Devos, Patrick Vourc'h, Christian Andres, and Philippe Corcia hereby state that they do not have anything to disclose.

\section{Statement of Authorship}

Hélène Blasco performed the statistical analysis, interpreted the data, and wrote the first draft of the manuscript. Guillaume Garcon acquired data and critically revised the manuscript for important intellectual content. Charlotte Veyrat-Durebex acquired data. Franck Patin acquired data. Judith Boyer acquired data. David Devos critically revised the manuscript for important intellectual content. Christian $\mathrm{R}$ Andres critically revised the manuscript for important intellectual content. Philippe Corcia 
recruited patients, interpreted data and critically revised the manuscript for important intellectual content.

\section{REFERENCES}

1. Andersen PM. Amyotrophic lateral sclerosis associated with mutations in the $\mathrm{CuZn}$ superoxide dismutase gene. Curr Neurol Neurosci Rep. 2006;6(1):37-46.

2. Chio A, Logroscino G, Traynor BJ, et al. Global epidemiology of amyotrophic lateral sclerosis: a systematic review of the published literature. Neuroepidemiology. 2013;41(2):118-30.

3. Shaw PJ, Forrest V, Ince PG, Richardson JP, Wastell HJ. CSF and plasma amino acid levels in motor neuron disease: elevation of CSF glutamate in a subset of patients. Neurodegeneration. 1995; 4(2):209-16.

4. Shibata N, Nagai R, Uchida K, et al. Morphological evidence for lipid peroxidation and protein glycoxidation in spinal cords from sporadic amyotrophic lateral sclerosis patients. Brain Res. 2001;917(1):97-104.

5. Fitzmaurice PS, Shaw IC, Kleiner HE, et al. Evidence for DNA damage in amyotrophic lateral sclerosis. Muscle Nerve. 1996; 19(6):797-8.

6. Chang Y, Kong Q, Shan X, et al. Messenger RNA oxidation occurs early in disease pathogenesis and promotes motor neuron degeneration in ALS. PLoS One. 2008;3(8):e2849.

7. Ferrante RJ, Browne SE, Shinobu LA, et al. Evidence of increased oxidative damage in both sporadic and familial amyotrophic lateral sclerosis. J Neurochem. 1997;69(5):2064-74.

8. Robelin L, Gonzalez De Aguilar JL. Blood biomarkers for amyotrophic lateral sclerosis: myth or reality? Biomed Res Int. 2014;2014:525097.

9. Carri MT, Valle C, Bozzo F, Cozzolino M. Oxidative stress and mitochondrial damage: importance in non-SOD1 ALS. Front Cell Neurosci. 2015;9:41.

10. Zoccolella S, Simone IL, Lamberti P, et al. Elevated plasma homocysteine levels in patients with amyotrophic lateral sclerosis. Neurology. 2008;70(3):222-5

11. Lovejoy DB, Guillemin GJ. The potential for transition metalmediated neurodegeneration in amyotrophic lateral sclerosis. Front Aging Neurosci. 2014;6:173.

12. Bowerman M, Vincent T, Scamps F, Perrin FE, Camu W, Raoul C. Neuroimmunity dynamics and the development of therapeutic strategies for amyotrophic lateral sclerosis. Front Cell Neurosci. 2013;7:214

13. Brooks BR, Miller RG, Swash M, Munsat TL. El Escorial revisited: revised criteria for the diagnosis of amyotrophic lateral sclerosis. Amyotrophic lateral sclerosis and other motor neuron disorders : official publication of the World Federation of Neurology, Research Group on Motor Neuron Diseases. 2000;1(5): 293-9.

14. Erel O. A novel automated direct measurement method for total antioxidant capacity using a new generation, more stable ABTS radical cation. Clin Biochem. 2004;37(4):277-85.

15. Garçon G, Leleu B, Marez T, et al. Biomonitoring of the adverse effects induced by the chronic exposure to lead and cadmium on kidney function: usefulness of alpha-glutathione S-transferase. Sci Total Environ. 2007;377(2-3):165-72.

16. Corazao-Rozas P, Guerreschi P, Jendoubi M, et al. A Mitochondrial oxidative stress is the Achille's heel of melanoma cells resistant to Braf-mutant inhibitor. Oncotarget. 2013;4(11):1986-98.

17. Dergham M, Lepers C, Verdin A, et al. Prooxidant and proinflammatory potency of air pollution particulate matter (PM(2). $(5)(-)(0) .(3))$ produced in rural, urban, or industrial surroundings in human bronchial epithelial cells (BEAS-2B). Chem Res Toxicol. 2012;25(4):904-19.

18. Bogdanov M, Brown RH, Matson W, et al. Increased oxidative damage to DNA in ALS patients. Free Radic Biol Med. 2000;29(7):652-8.

19. Mitsumoto H, Santella RM, Liu X, et al. Oxidative stress biomarkers in sporadic ALS. Amyotroph Lateral Scler. 2008;9(3):177-83.

20. Parakh S, Spencer DM, Halloran MA, Soo KY, Atkin JD. Redox regulation in amyotrophic lateral sclerosis. Oxid Med Cell Longev. 2013;2013:408681.

21. Weiduschat N, Mao X, Hupf J, et al. Motor cortex glutathione deficit in ALS measured in vivo with the J-editing technique. Neurosci Lett. 2014;570:102-7.

22. Babu GN, Kumar A, Chandra R, Puri SK, Kalita J, Misra UK. Elevated inflammatory markers in a group of amyotrophic lateral sclerosis patients from northern India. Neurochem Res. 2008; 33(6):1145-9.

23. Babu GN, Kumar A, Chandra R, et al. Oxidant-antioxidant imbalance in the erythrocytes of sporadic amyotrophic lateral sclerosis patients correlates with the progression of disease. Neurochem Int. 2008;52(6):1284-9.

24. Garcon G, Shirali P, Garry S, et al. Polycyclic aromatic hydrocarbon coated onto $\mathrm{Fe}(2) \mathrm{O}(3)$ particles: assessment of cellular membrane damage and antioxidant system disruption in human epithelial lung cells (L132) in culture. Toxicol Lett. 2000;117(1-2):25-35.

25. Garcon G, Garry S, Gosset P, et al. Benzo(a)pyrene-coated onto $\mathrm{Fe}(2) \mathrm{O}(3)$ particles-induced lung tissue injury: role of free radicals. Cancer Lett. 2001;167(1):7-15.

26. D'Amico A, Bertini E. Metabolic neuropathies and myopathies. Handb Clin Neurol. 2013;113:1437-55.

27. Ingre $C$, Roos PM, Piehl F, Kamel F, Fang F. Risk factors for amyotrophic lateral sclerosis. Clin Epidemiol. 2015;7:181-93.

28. Callaghan B, Feldman D, Gruis K, Feldman E. The association of exposure to lead, mercury, and selenium and the development of amyotrophic lateral sclerosis and the epigenetic implications. Neurodegener Dis. 2011;8(1-2):1-8.

29. Bowerman M, Salsac C, Coque E, et al. Tweak regulates astrogliosis, microgliosis and skeletal muscle atrophy in a mouse model of amyotrophic lateral sclerosis. Hum Mol Genet. 2015

30. Fiala M, Mizwicki MT, Weitzman R, Magpantay L, Nishimoto N. Tocilizumab infusion therapy normalizes inflammation in sporadic ALS patients. Am J Neurodegener Dis. 2013;2(2):129-39.

31. Prell T, Lautenschlager J, Weidemann L, Ruhmer J, Witte OW, Grosskreutz J. Endoplasmic reticulum stress is accompanied by activation of NF-kappaB in amyotrophic lateral sclerosis. J Neuroimmunol. 2014;270(1-2):29-36.

32. Tolosa L, Caraballo-Miralles V, Olmos G, Llado J. TNF-alpha potentiates glutamate-induced spinal cord motoneuron death via NF-kappaB. Mol Cell Neurosci. 2011;46(1):176-86.

33. Mitsumoto H, Factor-Litvak P, Andrews H, et al. ALS Multicenter Cohort Study of Oxidative Stress (ALS COSMOS): study methodology, recruitment, and baseline demographic and disease characteristics. Amyotroph Lateral Scler Frontotemporal Degener. 2014;15(3-4):192-203.

34. Hozumi I, Hasegawa T, Honda A, et al. Patterns of levels of biological metals in CSF differ among neurodegenerative diseases. J Neurol Sci. 2011;303(1-2):95-9.

35. Zoccolella S, Bendotti C, Beghi E, Logroscino G. Homocysteine levels and amyotrophic lateral sclerosis: A possible link. Amyotroph Lateral Scler. 2010;11(1-2):140-7.

36. Roos PM, Vesterberg O, Syversen T, Flaten TP, Nordberg M. Metal concentrations in cerebrospinal fluid and blood plasma from patients with amyotrophic lateral sclerosis. Biol Trace Elem Res. 2013;151(2):159-70. 